\title{
THE BEHAVIOR OF PEOPLE ON YOUTUBE BASED ON EXPERIMENTAL DATA
}

\author{
Olipriya Chakraborty \\ Student \\ Modern High School for Girls, Kolkata, West Bengal, India
}

\begin{abstract}
The 7-day experiment was conducted to find out the behavior of people on the social media platform of YouTube. It addressed whether people spend most of their time on YouTube watching education-based videos or entertainment-based videos. It was an experiment using a new method to take a fresh look at existing ideas. The research was conducted to find out the productivity of people on YouTube. Two YouTube channels were formed and a video posted every day and their views, as well as the new number of subscribers, were recorded every 24 hours. One of the channels was education-based while the other was entertainment-based. Finally, it was found out that the education-based channel had gained 4 new subscribers and the total number of views was 32. The entertainment-based channel, on the other hand, had gained 16 subscribers. The total number of views was 237. Thus, it can be effectively concluded that people tend to spend their time watching entertaining videos as opposed to educational videos on YouTube. It means they tend to spend their time less productively.
\end{abstract}

Keywords - YouTube, Experimental Data, Social Media

\section{INTRODUCTION}

People nowadays spend hours on the internet and social media. One of the most popular websites is YouTube. But what do people watch on YouTube every day? This experiment was held to find out whether people spend their time on YouTube for watching entertainment videos or educational videos. This experiment was held to find out whether people spend their time productively or not productively on their mobile phones and other devices every day.

\section{MATERIALS AND METHODS}

I have used the platform of YouTube to create two YouTube channels. The name of the first channel is BioInfo India and that of the second channel is JoJo ComicDubs. The former is an educational YouTube channel while the latter is an entertainment-based one. The first channel (BioInfo India) was created two months ago from Monday, 21 December 2020 and the second channel (JoJo Comic Dubs) was created on Monday, 21 December 2020. However, till December 21 only 2 videos were posted on BioInfo India. They were subsequently deleted forever before posting new videos on the YouTube channel so that the data would be as transparent as possible. New videos were posted every day, at almost the same time (as fast as possible for a person to post different videos on two channels simultaneously). The experiment was conducted from Monday, 21st December 2020 to Sunday, 27 December 2020 when a new video was posted for each of the 7 days on the two channels. The data was subsequently recorded.

\section{EXPERIMENT AND RESULT}

\section{On 21st December 2020}

New videos were uploaded for the first time.

Jojo ComicDubs- there was no prior subscribers to the channel since it had been created new. As shown in the image, the video premiered at 11.42 a.m. I shared the details of the channel among my network.

\section{Video published}

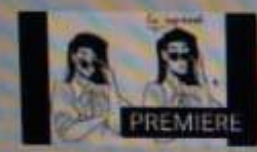

\section{Jo.Jo comic dub (funny)}

Share a link
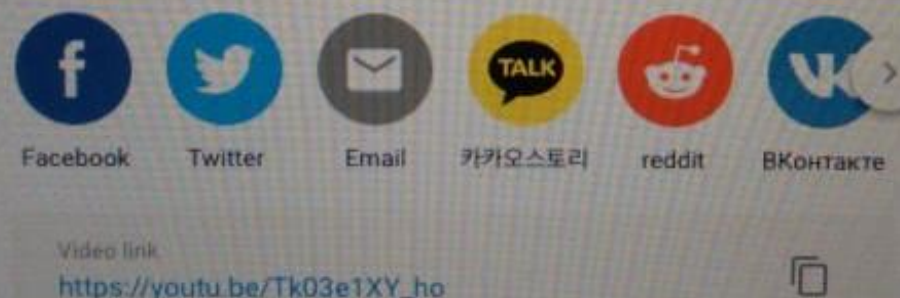
International Journal of Engineering Applied Sciences and Technology, 2021

Vol. 5, Issue 10, ISSN No. 2455-2143, Pages 257-264

Published Online February 2021 in IJEAST (http://www.ijeast.com)

BioInfo India- As mentioned earlier, although the channel was started 2 months ago only two videos were uploaded which were removed before adding the new video as a part of the experiment. It already had 10 subscribers before starting this experiment. I shared the details of this channel too among my network to place both the channels on an equal footing. This video premiered at 11.45 a.m.

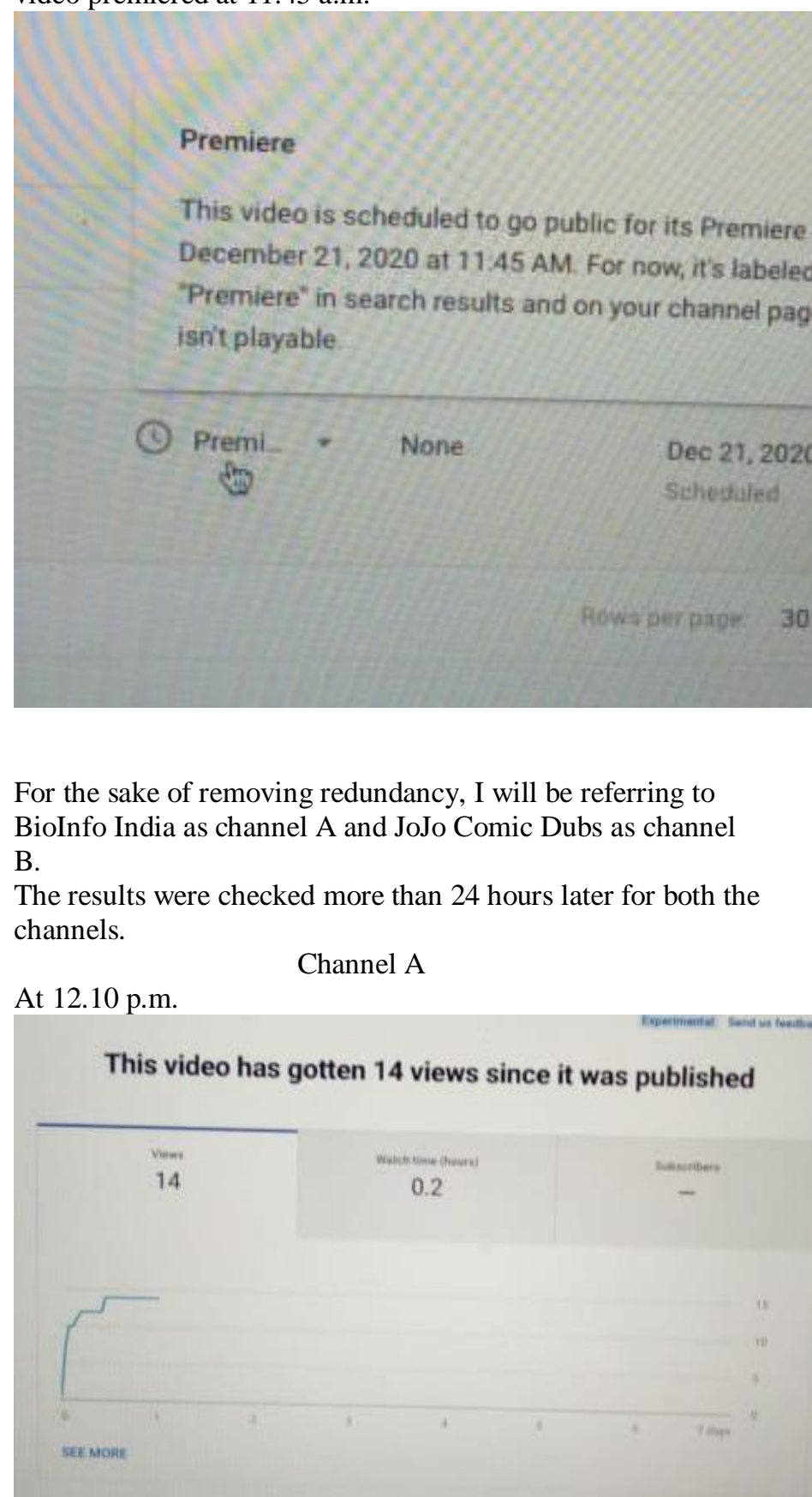

+7 subscribers

+28 views

On 22nd December 2020

Channel A

\section{Video published}

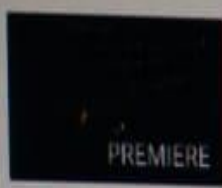

Structure of Prokaryotic Cells

Scheduled Dec 22, 2020, 12:29 PM

Share a link
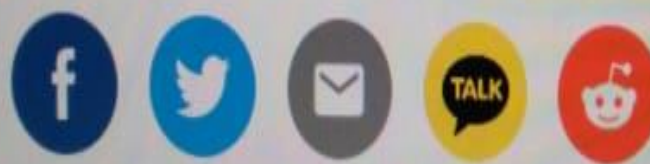

Facebook

Twitter

Email

reddit

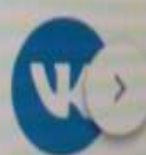

ВКонтакте

Video link

https://youtu.be/lamXUxh2a8A

+4 subscribers

+14 views

Channel B 
International Journal of Engineering Applied Sciences and Technology, 2021

Vol. 5, Issue 10, ISSN No. 2455-2143, Pages 257-264

Published Online February 2021 in IJEAST (http://www.ijeast.com)

Channel B

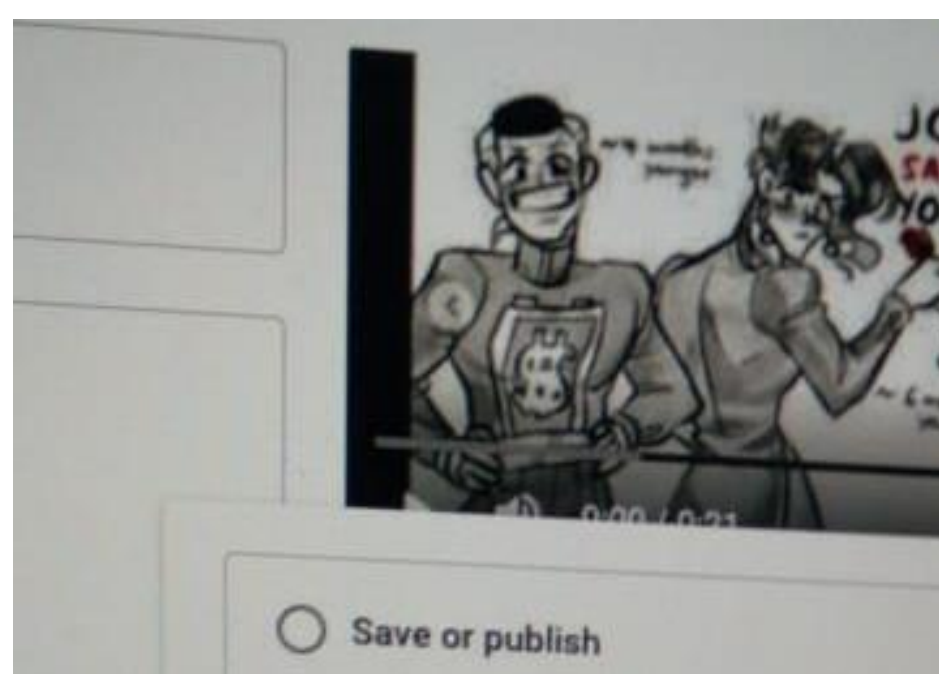

Schedule

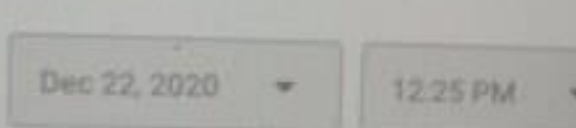

A public watch page will be created in shov date

Set as Premiere (2)

\section{+0 subscribers}

+5 views

Channel B

11.39 a.m.

is Video analytics

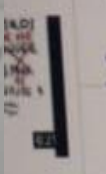

-

This video has gotten 54 views since it was published
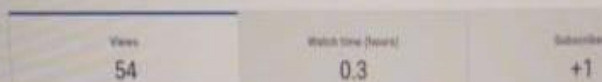

The views were again checked almost 24 hours later

Channel A

11.37 a.m.

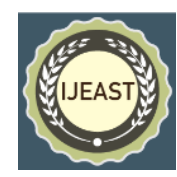

published

Alealiane

5

sents -

nilesenes

smatare

Oumerem:

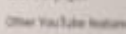

sin uent

mat wouk

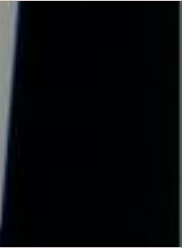

Reatione

54

+1 subscribers

+54 views

On 23rd December 2020

Channel A 
International Journal of Engineering Applied Sciences and Technology, 2021

Vol. 5, Issue 10, ISSN No. 2455-2143, Pages 257-264

Published Online February 2021 in IJEAST (http://www.ijeast.com)

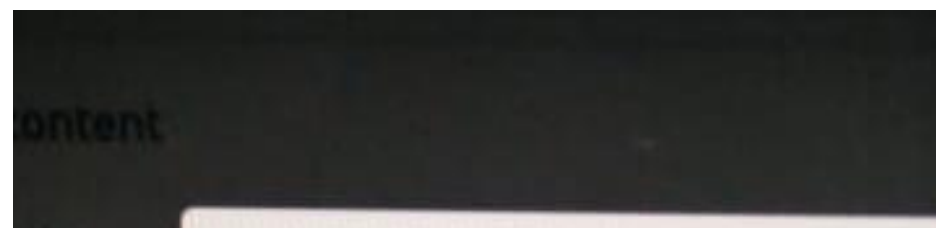

Video published

A walkthrough of the Official Khan I

Scheduled Dec 23, 2020 11 49 AM ideo analytics

Asach Engagement autience

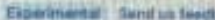

This video has gotten 3 views since it was published

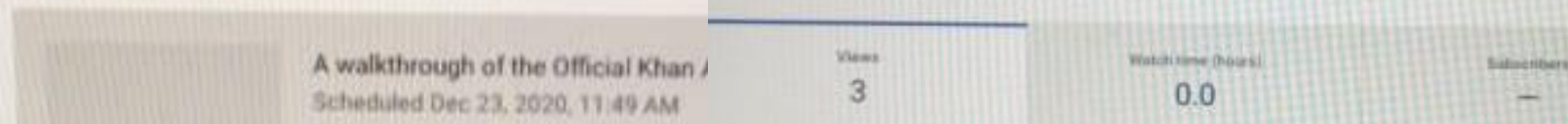

EREMIERE

Share a link

f

Facebook

video link

htipsi/lyoutu be/A4SBEBDw7nd

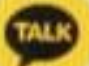

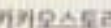

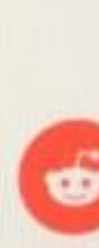

teddit
Channel B

Video published at 11.45 a.m

The views were checked almost 24 hours later Channel A

11.45 a.m.
wI Monte

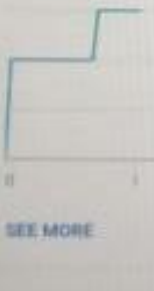

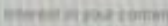

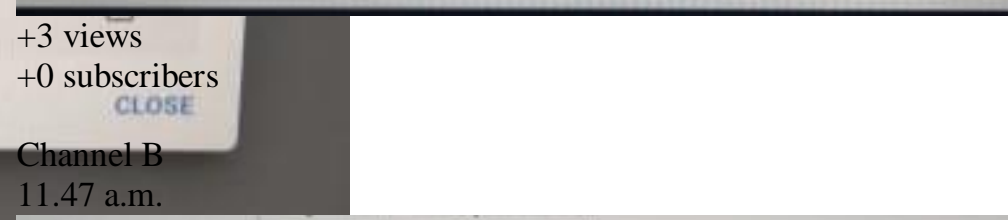

Video analytics

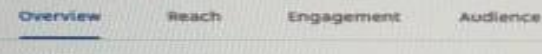

This video has gotten 62 views since it was publis

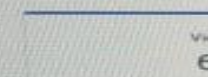

0.5

+62 views

+0 subscribers

On 24th December 2020

Channel A 
International Journal of Engineering Applied Sciences and Technology, 2021

Vol. 5, Issue 10, ISSN No. 2455-2143, Pages 257-264

Published Online February 2021 in IJEAST (http://www.ijeast.com)

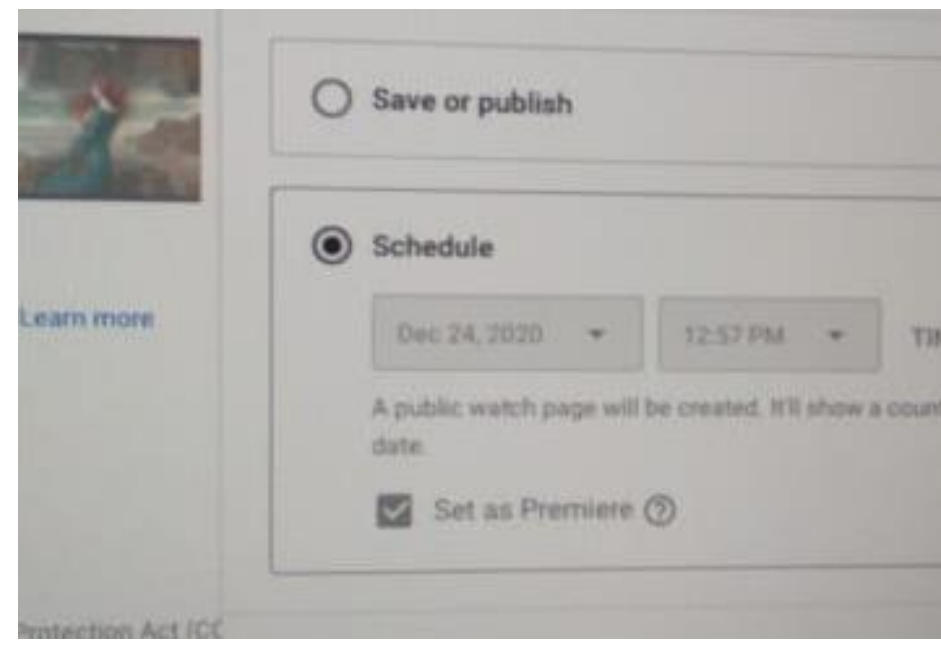

Channel B

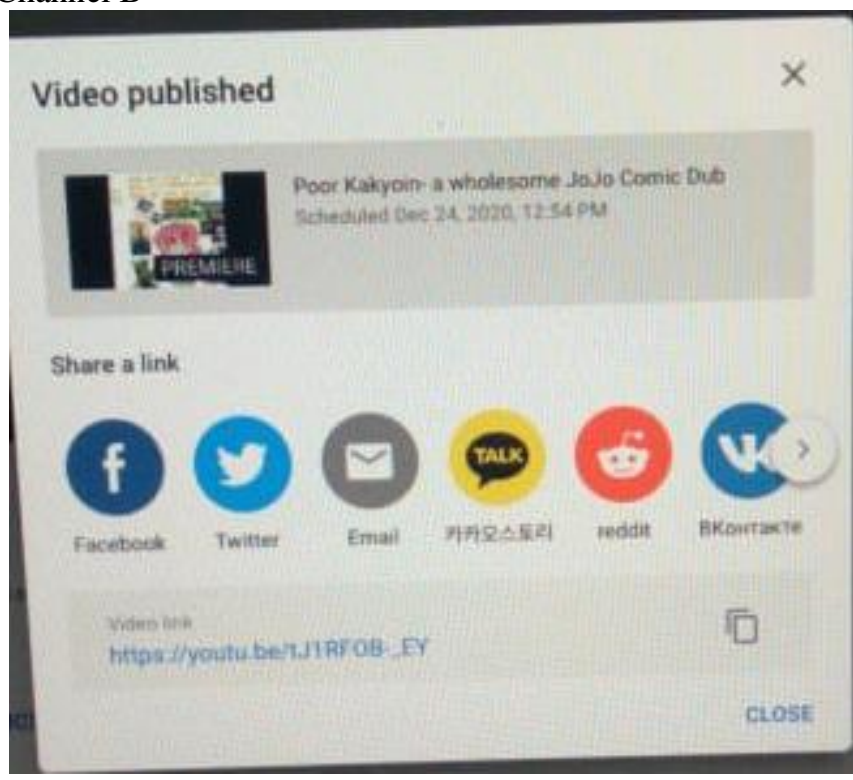

On checking the views almost 24 hours later,

Channel A

At 11.01 a.m.

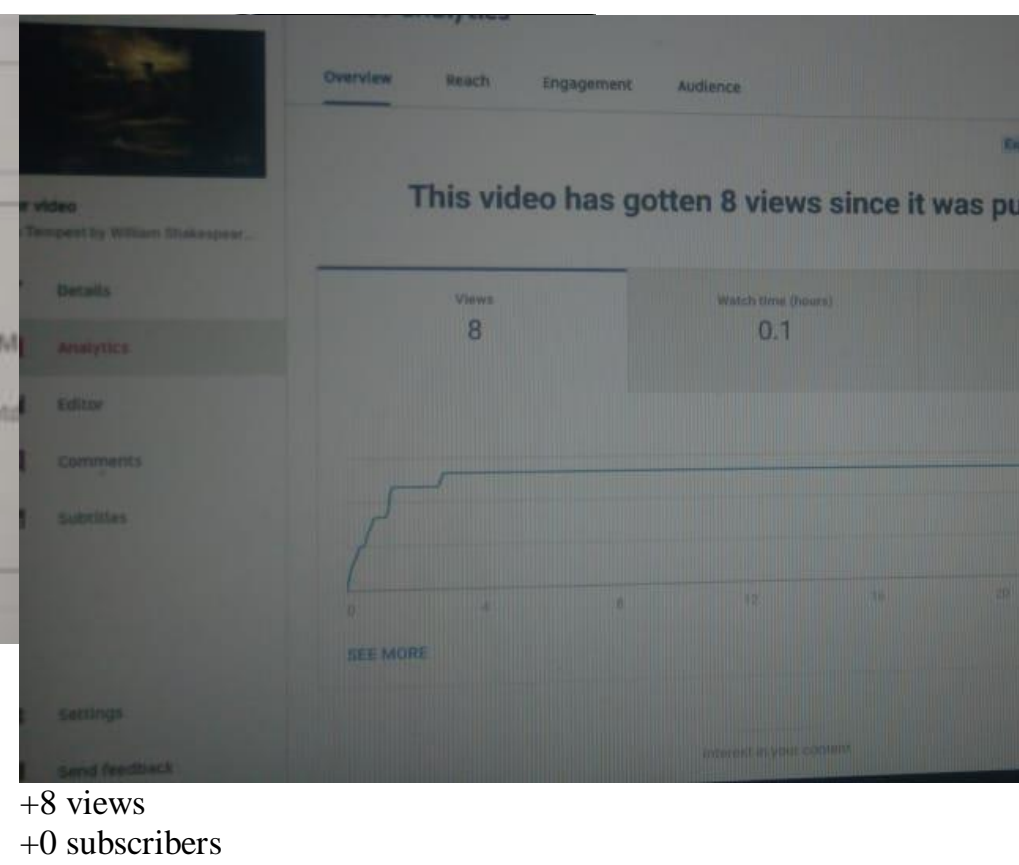

Channel B

At 11.02

a.m
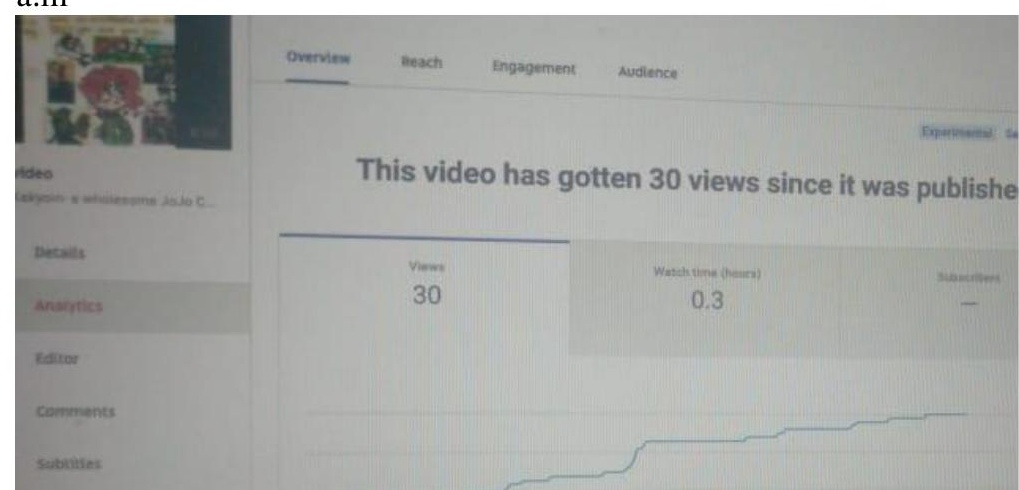

+30 views

+3 subscribers

On 25th December 2020

Channel A 
International Journal of Engineering Applied Sciences and Technology, 2021

Vol. 5, Issue 10, ISSN No. 2455-2143, Pages 257-264

Published Online February 2021 in IJEAST (http://www.ijeast.com)

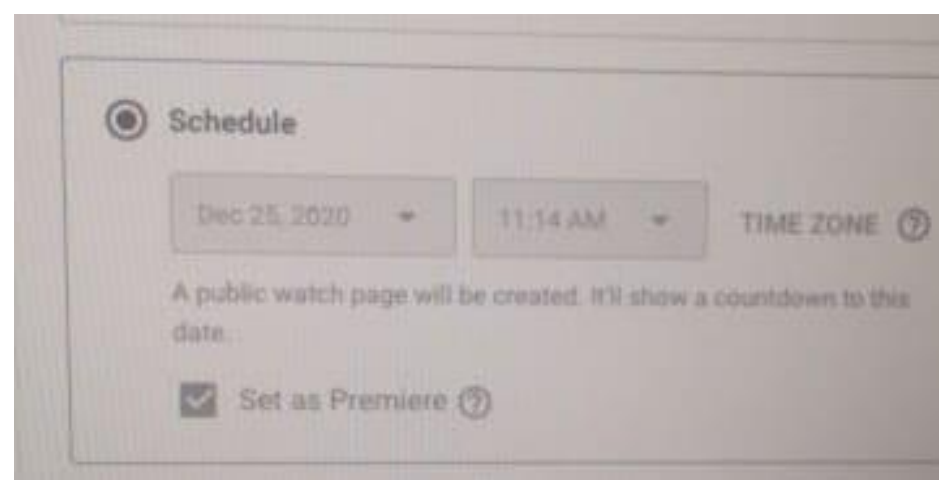

11.17a.m.
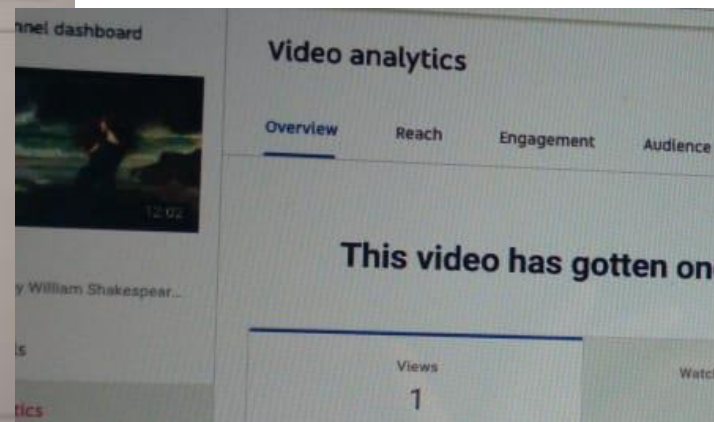

This video has gotten one view since it was pu

Channel B
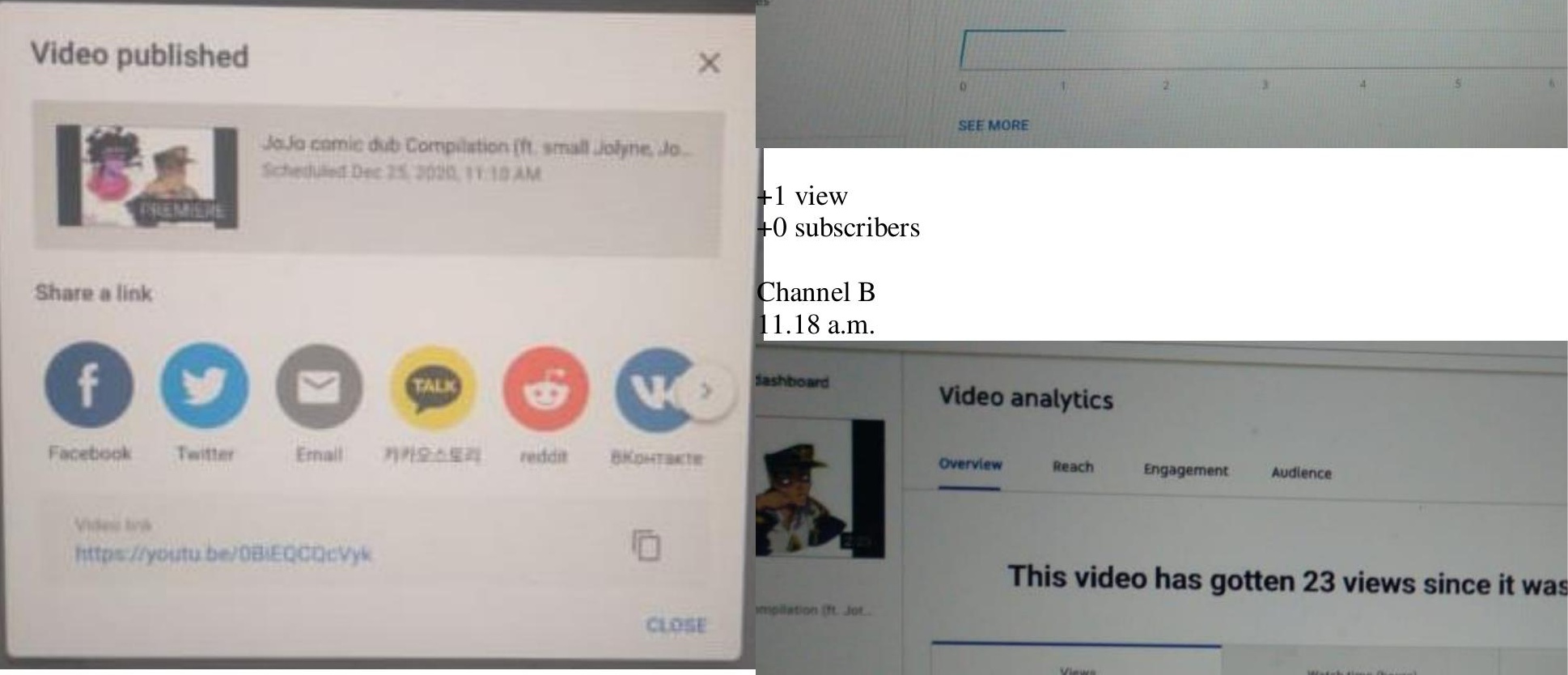

The number of views was checked almost 24 hours later. Channel A

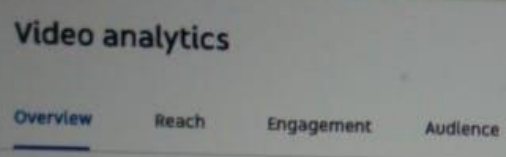

This video has gotten 23 views since it was

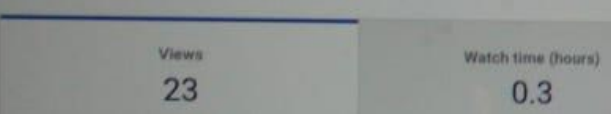

+23 views

+0 subscribers

26th December 2020

Channel A

Video uploaded at 11.35 a.m.

Channel B 
International Journal of Engineering Applied Sciences and Technology, 2021

Vol. 5, Issue 10, ISSN No. 2455-2143, Pages 257-264

Published Online February 2021 in IJEAST (http://www.ijeast.com)
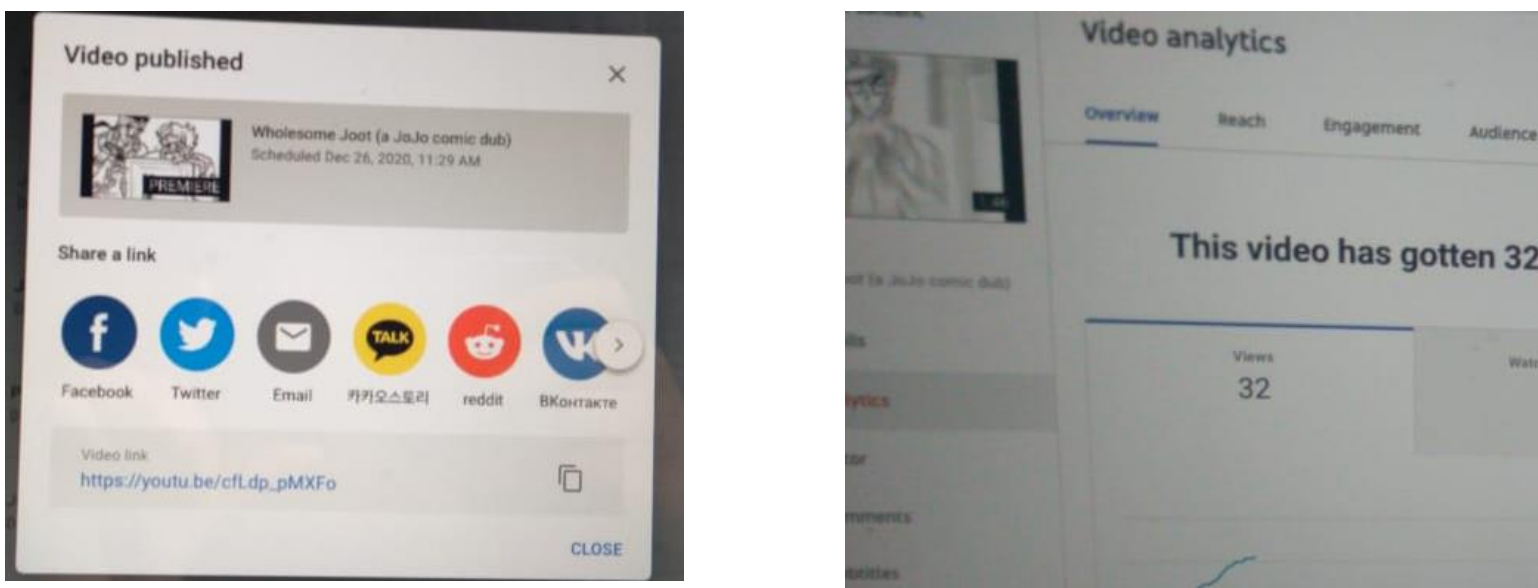

This video has gotten 32 views since it was pu

The views were checked more than 24 hours later Channel A

1.20 p.m.

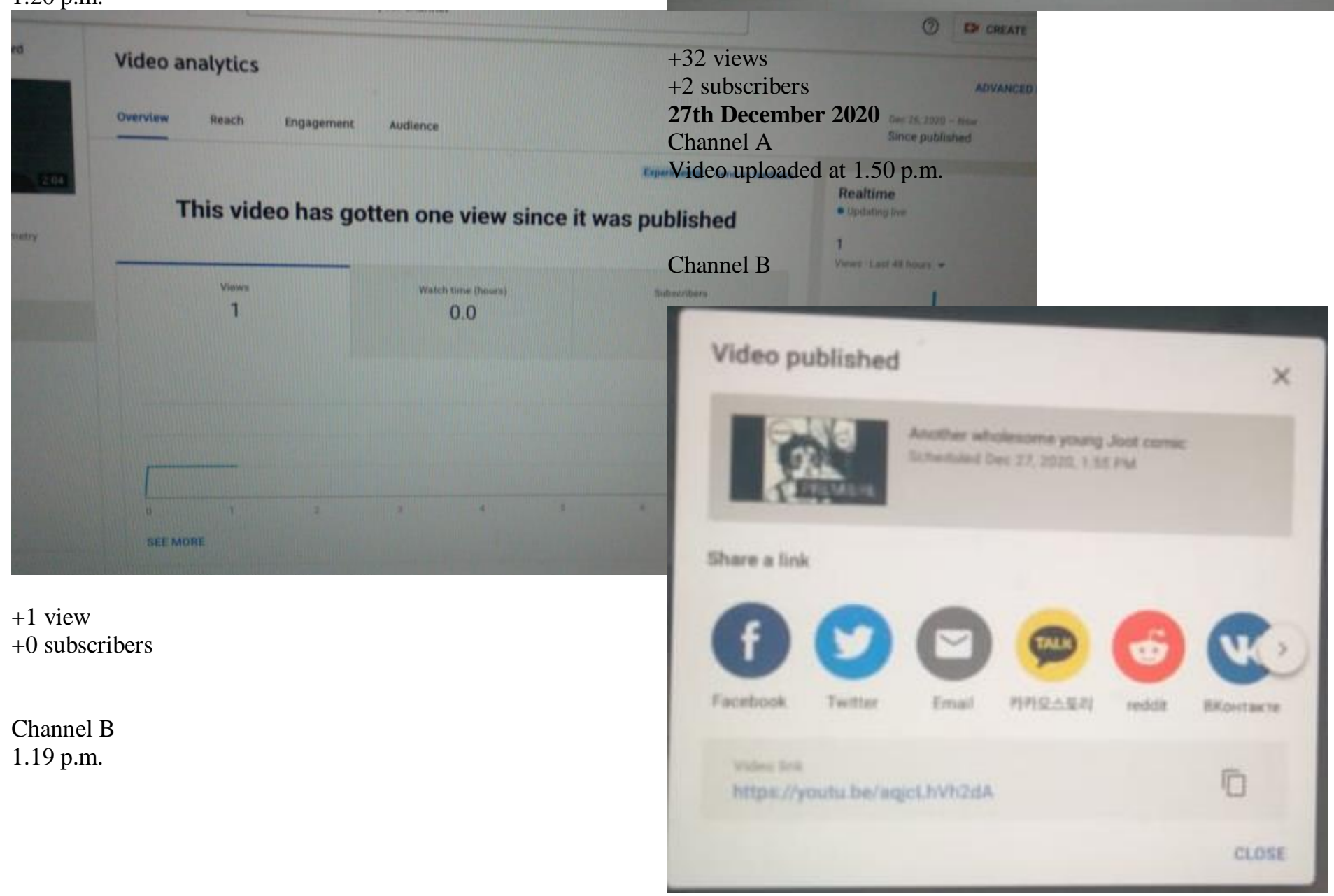


At 1.37 p.m., channel A had no views and had gained no subscribers while at 1.39 p.m. channel B had 8 views and gained 3 subscribers.

\section{CONCLUSION}

At the end of 7 days, it was seen that the results were the following-

Channel A (the education-based channel) had gained 4 subscribers. The total number of views was 32 .

Channel B (entertainment-based channel) had gained 16 subscribers. The total number of views was 237 .

It is to be noted that the number of views within the 24 hours was added up. New views after the 24 hour period were not counted.

Thus it was seen that people spend a considerable more amount of time watching entertainment based videos compared to educational videos. Thus, people are more likely to spend their time unproductively on the social media platform of YouTube.

\section{REFERENCE}

[1] Kemp Simon (2020) .DIGITAL 2020: GLOBAL DIGITAL OVERVIEW (Pg- 125-128)

[2] Chandramouli, Rajesh (2020). Social media usage jumps $87 \%$ as people spend over 4 hours daily (Pg-12-18)

[3] Pihlaja, Stephen (2014) Antagonism on YouTube Metaphor in Online Discourse (https://doi.org/10.5040/9781472593740)

[4] Eisemann C. (2015) Was ist YouTube?. In: C Walk auf YouTube. Digitale Kultur und Kommunikation, vol 3. Springer VS, Wiesbaden. (https://doi.org/10.1007/9783-658-06429-7_4)

[5] Strangelove, Micahel (2010) Watching YouTube (https://doi.org/10.3138/9781442687035-013)

[6] Eric Kin, Wai Lau (2017) Knowldege sharing on YouTube (Pg- 3-4)

[7] Paul Haridakis Ph.D \& Gary Hanson M.A. (2009) Social Interaction and Co-Viewing With YouTube: Blending Mass Communication Reception and Social Connection, Journal of Broadcasting \& Electronic Media, 53:2, 317

335, DOI: $10.1080 / 08838150902908270$

[8] Smith,Tom (2009) Conference Notes - The Social Media Revolution. International Journal of Market Research. ;51(4):559-561. doi:10.2501/S1470785309200773

[9] Rowntree, D. (1981). Statistics without tears: A primer for non-mathematicians. Scribner Book Company.(pg24-28)

[10] Marta Dynel (2014) Participation framework underlying YouTube interaction, Journal of Pragmatics (Pages 37-52) 